\title{
An Adaptive Overcurrent Coordination Scheme to Improve Relay Sensitivity and Overcome Drawbacks due to Distributed Generation in Smart Grids
}

\author{
Meng Yen Shih, Arturo Conde, Member, IEEE, Zbigniew Leonowicz, Senior Member, IEEE and Luigi \\ Martirano, Senior Member, IEEE
}

\begin{abstract}
Distributed Generation (DG) brought new challenges for protection engineers since standard relay settings of traditional system may no longer function properly under increasing presence of DG. The extreme case is coordination loss between primary and backup relays. The directional overcurrent relay (DOCR) which is the most implemented protective device in the electrical network also suffers performance degradation in presence of DG. Therefore, this paper proposes the mitigation of DG impact on DOCR coordination employing adaptive protection scheme (APS) using differential evolution algorithm (DE) while improving overall sensitivity of relays. The impacts of DG prior and after the application of APS are presented based on interconnected 6 bus and IEEE 14 bus system. As a consequence, general sensitivity improvement and mitigation scheme is proposed.
\end{abstract}

Keywords--Adaptive protection scheme; directional overcurrent relay coordination; distributed generation; differential evolution algorithm; smart grid.

\section{INTRODUCTION}

$\mathrm{D}$ ISTRIBUTED Generation (DG) in the form of renewable energy sources has become one of the most discussed topics nowadays. The scope to depart from traditional generation plants for long term economic and environmental benefits has made a massive increase of interests in DG technologies. Moreover, DGs can contribute to important aspects such as: network reliability, line congestion relief, overall loss reduction, and generation cost reduction in smart grid [1-8].

Despite of the numerous advantages of having DGs installed in the network, there are also new challenges [9-14] and negative impacts on the protective overcurrent relays (OCRs). Those are mainly increase of short-circuit current during fault

M. Y. Shih is with the Division of Science and Engineering, University of Quintana Roo, Quintana Roo, Mexico (e-mail: sonofafriend@gmail.com)

A. Conde is with the Faculty of Mechanical and Electrical Engineering, Autonomous University of Nuevo Leon, Nuevo Leon, Mexico (e-mail: con_de@yahoo.com)

Z. Leonowicz is with the Faculty of Electrical Engineering, Wroclaw University of Science and Technology, Wroclaw, Poland (e-mail: zbigniew.leonowicz@pwr.edu.pl)

L. Martirano is with the Department of Astronautics, Electrical and Energetics, Sapienza University of Rome, Rome, Italy (e-mail: luigi.martirano@uniroma1.it) condition and the bi-directional load flow in radial lines which the elements of the network are not designed to operate under these new conditions. Possible consequences to the protection system are false tripping, under/over reach of relays, and coordination loss between primary and backup relays [9-10,1522].

Several solutions have been proposed to mitigate the impact of DG penetration on sub-transmission and distribution networks, like:

- disconnection of DGs immediately after fault detection [23],

- $\quad$ limitation of installed DGs capacity [24-26],

- modification of the protection system by installing more breakers for sectionalization, reconfiguration of networks or the use of distance relays and/or directional overcurrent relays [27-30],

- installation of fault current limiters (FCLs) to preserve/restore the original relay settings [18, 31-42],

- fault ride through control strategy of inverter based DGs [43],

- fault current control by solid-state-switch-based field discharge circuit for synchronous DGs [44],

- $\quad$ adaptive protection schemes (APS) [20, 45-54].

Although these methods can adequately mitigate the negative impacts of DGs penetration on performance of the protective relays, they suffer several limitations as well. Disconnecting large DGs immediately after fault detection may lead to severe voltage sags as the contribution of reactive power from DGs will be cut off. Moreover, most faults are temporary, thus disconnecting the DGs isn't economically beneficial since the DGs will need to be reconnected to the network after the clearance of temporal fault in order to profit from the renewable energy. Also, stability problem may occur if there were high penetrations of DGs in the network.

Limiting the DGs capacity is a provisional solution, since renewable energy is cheap, it should be fully exploited to gain more profit and also to avoid excess $\mathrm{CO}_{2}$ emission mostly generated from conventional power plants.

Modifying the protection scheme by installing more breakers for sectionalization, reconfiguration of networks or change of protection principles is costly, and also the use of numerous protection principles in a certain area of the power system may lead to more complicated protection coordination scenario and difficult post-event analysis. 
Installing FCLs to preserve/restore the original relay settings are practical since this device has almost zero impedance in steady-state operation mode and inserts high impedance in series with the system when a fault occurs to limit the fault magnitude to its previous magnitude before DG installation. But this implies an advanced study of optimal impedance and location of the FCLs. Moreover, the major drawback of broad implementation of FCLs is the additional and elevated cost which is undesirable for both utility and DG owners.

Both the fault ride-through control strategy of inverter based DGs and fault current control by solid-state-switch-based field discharge circuit for synchronous DGs are low-cost solution compared to the previous ones. The first consists of a commutation control strategy of the inverter switches in order to limit the fault current contribution. The second consists of installing a solid-state-switch-based field discharge circuit for synchronous DGs in order to drain the excess fault currents. However, both are only partial solutions to the problem since the first solution is only applicable to inverter-based DGs and the second only to synchronous DGs. These shortcomings lead to another option, the adaptive protection scheme (APS).

The APS proposed in this research [54] consists of automatic online re-adjustment of relay settings so that the relays are best attuned for different network operating condition due to dispatch or natural condition. Such changes are variations of inputs and outputs of generators and transmission lines that affect the load flow and fault current distribution. The APS may require a central host with powerful computer that is linked by communication channels to send/receive data to/from relays prior or after disturbance. Integration of substation control and data acquisition (SCADA) and energy management system (EMS) will be needed to effectively implement this scheme. Contemporary directional overcurrent relays (DOCRs) have memory capacity and can be remotely re-adjusted through communication channels. Hence the DOCRs, SCADA system along with an appropriate online optimization algorithm for coordination of DOCRs, can potentially improve the degraded performance of relays caused by DGs. Therefore, this method can be very beneficial in the long term view for modern smart grids.

Differential evolution algorithm (DE) was selected for the coordination study since it has been reported to be very efficient in different areas [55-56]. DE had outperformed genetic algorithm (GA), particle swarm optimization (PSO), harmony search algorithm (HS) and seeker optimization algorithm (SOA) in the coordination study [57].

\section{SMART GRID AND DG IMPACT ON PROTECTIVE RELAY}

\section{A. Smart Grid}

Smart Grid targets highly reliable, self-healing, selfregulating, demand response, efficient and cutting edge network that allows integration of high penetration of renewable energy sources [1-8]. An illustration of smart grid scheme is presented in Fig. 1.

A general definition follows the Electric Power Research Institute (EPRI) Smart Grid Resource Center, "A Smart Grid is one that incorporates information and communications technology into every aspect of electricity generation, delivery and consumption in order to minimize environmental impact, enhance markets, improve reliability and service, and reduce costs and improve efficiency." [58]. Therefore, the proposal will rely on these advanced information and communication technologies to perform adaptive and online coordination of DOCRs.

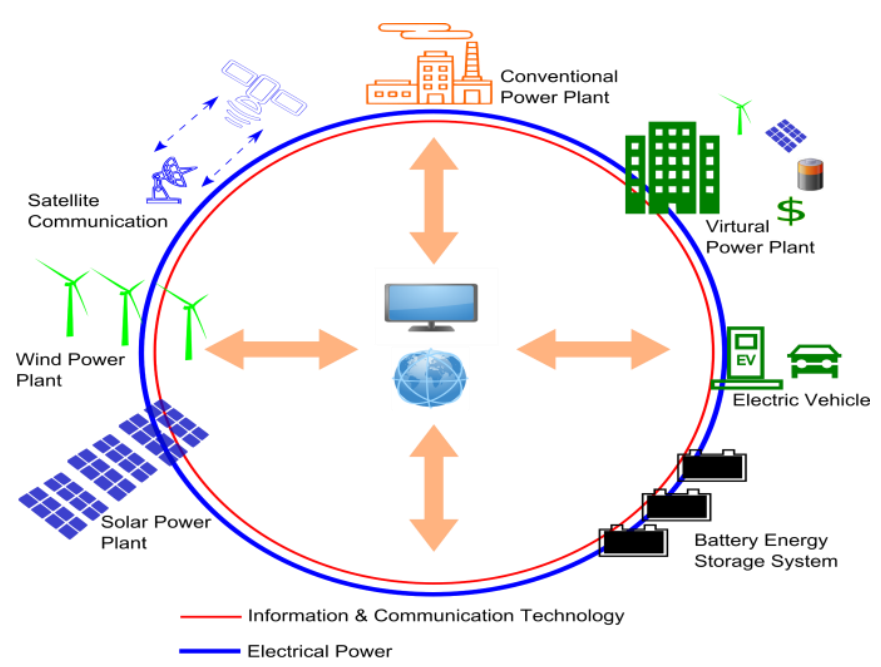

Information \& Communication Technology + Distributed Generation = Smart Grid Fig. 1. Smart Grid: general schematic presentation.

\section{B. Impact of DG on Protective Overcurrent Relay}

\section{1) Coordination Loss:}

The loss of coordination is defined as the violation of coordination time interval (CTI) constraint between the primary and backup relay $[18,20,57]$. Example: for a given fault at point F in Fig. 2, the coordination pairs to be analyzed in this scenario are R7-R8 and R7-R9 [primary-backup]. Due to the penetration of DG, these relays all sense an increase of short-circuit current. For R7, this is not critical as it is the primary relay. But for R8 and R9, their CTI with respect to R7 may not be fulfilled as when there was no presence of DG. Therefore, there is a loss of coordination between pairs R7-R8 and R7-R9.

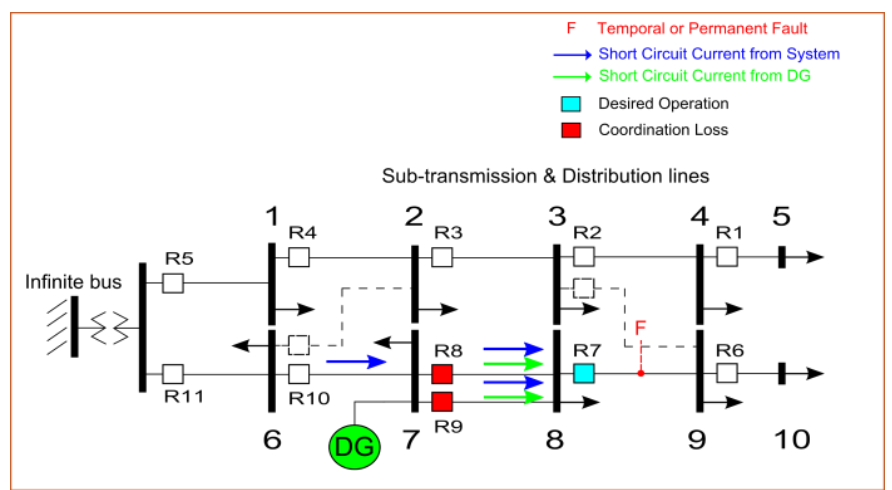

Fig. 2. Loss of coordination due to DG penetration.

A graphical illustration of coordination loss using inverse time relay characteristic curve for the coordination pair R7-R8 
is presented in Fig. 3. It can be clearly seen that after the integration of DG, the backup relay R8 accelerates its tripping time due to the increase of fault current; whereas the primary relay R7 is barely affected because its tripping time is already located at the horizontal asymptote curve. Hence, there is a loss of coordination because CTI is no longer preserved for the coordination pair R7-R8.

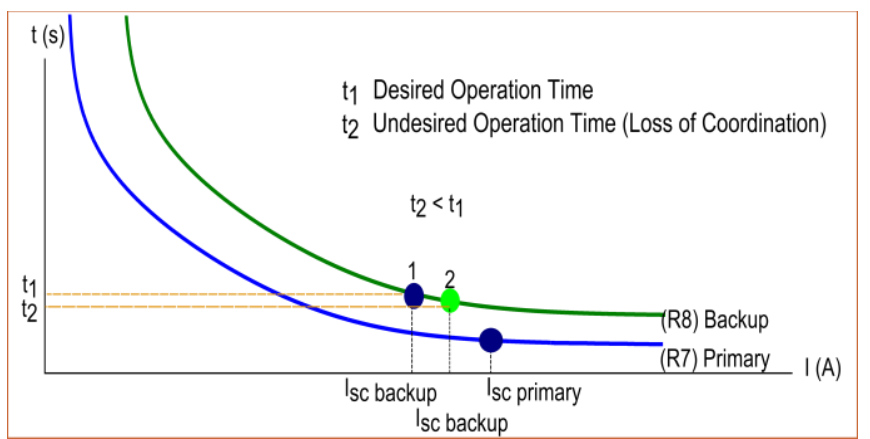

Fig. 3. Illustration: Loss of coordination due to DG penetration.

\section{2) Islanding Operation:}

The islanding operation is defined as the isolation of a certain part of a network from the main network due to dispatch or natural condition [53,59-62]. For a given fault at point $F$ in Fig. 4, suppose that relay R10 successfully cleared the permanent fault by tripping the circuit breaker. Then the remaining circuit from bus 7 to 10 will form an island operation network (micro-grid) fed by the DG (assuming that the DG has sufficient capacity to maintain stable operation for the islanded network). Under new network operating condition if a fault occurs at any point along the lines between buses 7 to 10; then both primary and backup relays will suffer significant time delay in clearing the fault due to the relatively small fault current contribution by the DG. The relays can regain their operation speed if they were re-adjusted/re-coordinated for this new network operation and topology.

$$
I_{s c}^{D G}<I_{s c}^{\text {system }}
$$

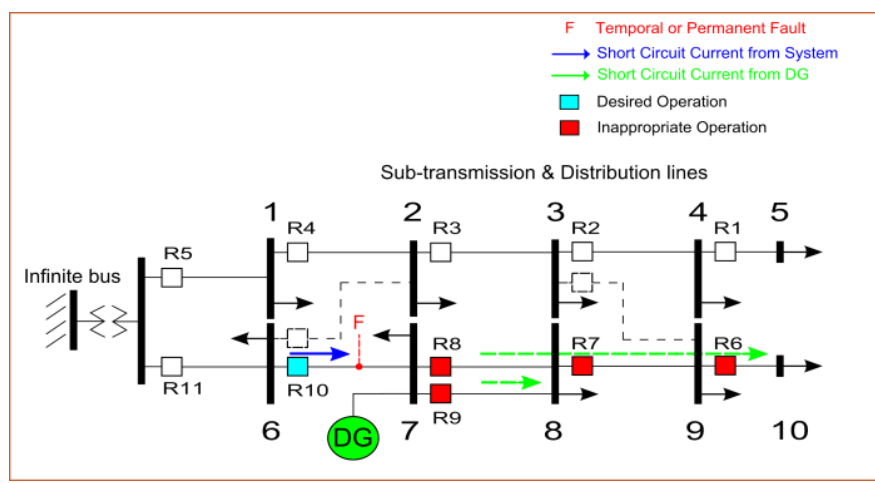

Fig. 4. Inappropriate relay delay operations due to intentional or unintentional islanding (DG micro-grid).

This can cause further problems such as load or source tripping. Many industrial motors have under-voltage tripping protection, so if the fault takes long time to clear then the voltage sag duration increases which may lead to a disconnection of industrial loads. The same applies to some power sources (ie: wind turbine generators), which disconnect from the network after several seconds for small sag or immediately after big sag.

A graphical illustration of an inappropriate relay delay operation using inverse time relay characteristic curve for the coordination pair R7-R8 is presented in Fig. 5. It can be clearly seen that after entering island operation mode, the backup relay R8 increases its tripping time due to the decrease of fault current; whereas the primary relay is barely affected because its tripping time is already located at the horizontal asymptote curve. Hence, there will be an undesired backup tripping time if a fault occurs during island operation mode.

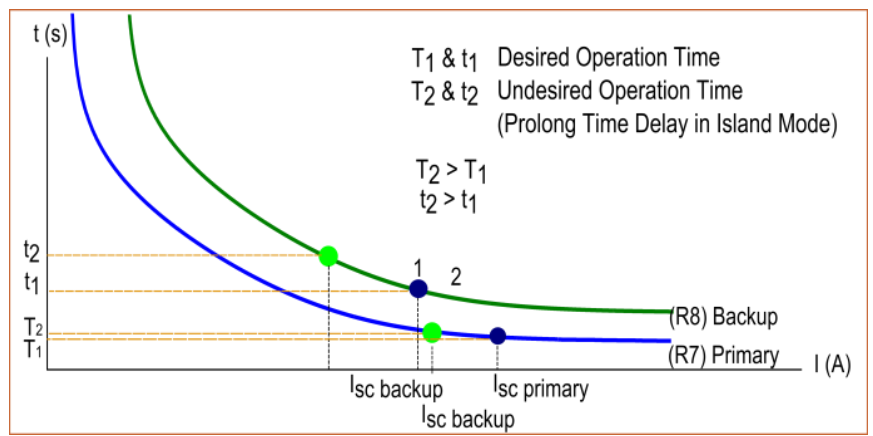

Fig. 5. Illustration: Inappropriate relay delay operations due to intentional or unintentional islanding (DG micro-grid).

\section{PROTECTION COORDINATION SCHEME}

Detailed description of the adaptive protection scheme and the formulation of coordination problem are presented in the following sections.

\section{A. Description of Adaptive Protection Scheme}

The adaptive protection scheme for coordination of DOCRs including DGs is presented in Fig. 6.

The proposed idea [54] for mitigating the impacts of DGs on DOCR coordination is based on a centralized adaptive scheme. This protection scheme consists of a centralized processing server which analyzes and optimizes the data obtained through SCADA system of the network that implements overcurrent protection principle. The SCADA system monitors the network condition and identifies the operational and topological changes of the network. As soon as a change in the network is identified, the latest breaker and network configuration and/or the status of DGs are input into the centralized processing server. Based on the network status data, the server performs load flow, fault, contingency and sensitivity analysis. Then, it recalculates the pickup current of relays and optimizes the DOCR coordination. The new settings are updated to the DOCRs via communication network so that the DOCRs become best-tuned to the present network operating condition. A single cycle is then completed. For every change of new operating condition, the cycle is executed again. The frequency will also be in function of wind and solar forecast since DGs are intermittent sources. 


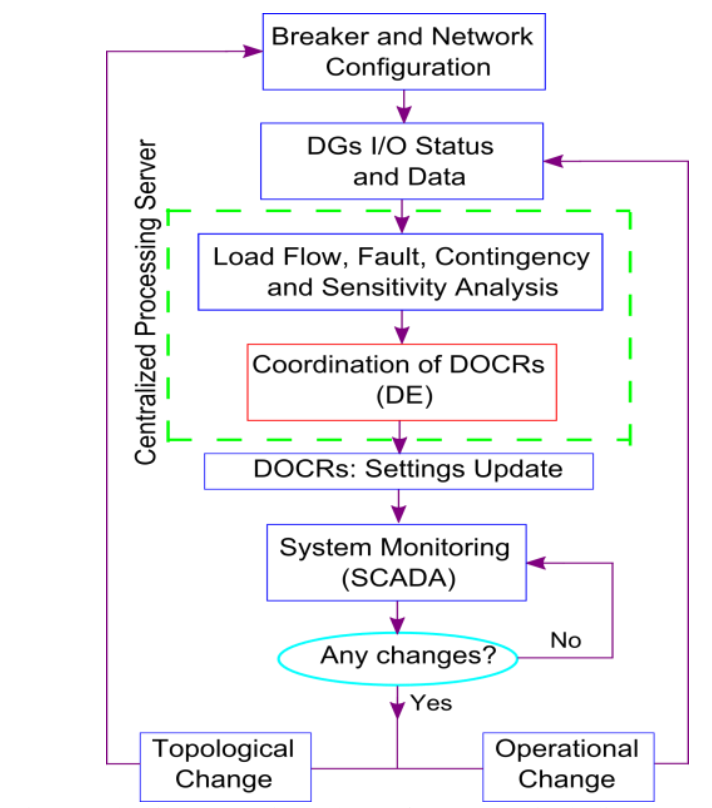

Fig. 6. Adaptive protection scheme for DOCRs including DGs.

\section{B. Formulation of Coordination Problem}

\section{1) Objective Function:}

The purpose of formulating the coordination of DOCRs as an optimization problem is to minimize the primary and backup operation time of relays while maintaining selectivity of relays' operation. It is of great importance to establish appropriate objective function that evaluates the fitness of the settings because this is the key to ensure optimum solution using optimization algorithms. The fitness function is given in (1):

$$
\begin{gathered}
\text { fitness }=\left(\frac{N V}{N C P}\right)+\left(\frac{\sum_{\mathrm{a}=1}^{N C P} t_{p_{a}}}{N C P}\right) * h_{1}+\left(\frac{\sum_{b=1}^{N C P} t_{b_{b}}}{N C P}\right) * h_{2}+ \\
\left(\sum_{\mathrm{L}=1}^{N C P} E_{C_{C T I}}\right) * h_{3}
\end{gathered}
$$

where $h_{1}, h_{2}$ and $h_{3}$ are factors that increase or decrease the influence of each sub-objective function, $N V$ is the number of violation of coordination constraints, $N C P$ is the number of coordination pairs, $\mathrm{t}_{\mathrm{pa}}$ is the primary operation time of relay $a$ for near-end fault, $\mathrm{t}_{\mathrm{b}}$ is the backup operation time of relay $b$ for far-end fault, and $E_{C T I L}$ is the $C T I$ error of $L$-th coordination pair.

The $t_{b_{b}}$ minimizes the backup operation time of relays, the $E_{C T I_{L}}$ minimizes the $C T I$ to as close to $0.3 \mathrm{~s}$ as possible, the $N V$ minimizes the number of violations to zero (avoid converging to a local minimum) and the $t_{p_{a}}, t_{b_{b}}$, and $N V$ are all scaled and divided by $N C P$ to be able to sum together. These different values need to be included in the objective function because it was observed that the use of only $t_{p_{a}}$ in the objective function for coordination in larger meshed systems may converge at a result where there may be higher backup time, higher $C T I$ and may have violation of constraints. Therefore, the $t_{b_{b}}, E_{C T I_{L}}$ and $N V$ are included in the objective function to further improve the results while maintaining selectivity.

\section{2) Primary and Backup Relay Constraints:}

To coordinate the relays, there must be a time difference between the primary and backup relay. This time difference is called coordination time interval (CTI). In this way, whenever the primary relay fails to extinct a fault, the backup relay enters and tries to extinct the fault after a pre-specified delay. This delay is usually set between 0.2 and 0.5 seconds, and 0.3 seconds is used in this paper. The coordination constraint for every coordination pair is given in (2):

$$
C T I \leq t_{b}-t_{p}
$$

where CTI is the pre-defined CTI, $t_{p}$ is the primary operation time for near-end fault, and $t_{b}$ is the backup operation time for far-end fault.

There is also a range for each relay setting where feasible solutions can be found. This is given in (3) and (4):

$$
\begin{gathered}
\text { dial }_{\text {min }} \leq \text { dial } \leq \text { dial }_{\text {max }} \\
I_{\text {pickup }_{\text {min }}} \leq I_{\text {pickup }} \leq I_{\text {pickup }} \text { max }
\end{gathered}
$$

where dial is setting within range [0.05-10] for most numerical relays, and $I_{\text {pickup }}$ is the relay pickup current that consists of a temporal overload and security factor $(k)$ that multiplies the maximum load current. The $k$ value is normally set to be between $140 \%$ and $160 \%$ [63].

The minimum and maximum values of dial and pickup settings are both hardware limitations. The dial parameter is a family of curves of the same type, which moves up or down to enable coordination among relays for certain tripping time [6364]. Minimum dial settings are often used to obtain faster relay tripping time. But this must be analyzed as it may compromise the selectivity or coordination of relays. On the other hand, the pickup current settings apart from the hardware limitation of upper and lower bounds, must have a minimum bound limitation which can tolerate common temporal overloading scenarios [63-64]. Also, an upper bound is set, since as pickup setting increases, sensitivity decreases. And relays may delay too much to trip or never trip if pickup setting is set too high when a two phase fault occurs.

\section{3) Relay Characteristic Curve:}

The time overcurrent relay functions are set according to the relay characteristic curve (inverse time curve). IEEE standard C37.112-1996 [65] is followed in this paper and is given in (5):

$$
t=\left[\frac{A}{\left(\frac{{ }_{\text {sc } c^{\oplus} \max }}{I_{\text {pickup }}}\right)^{p}-1}+B\right] * \text { dial }
$$

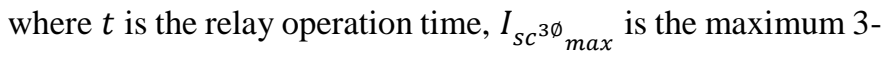
phase short circuit current and $A, B, p$ are constants of the IEEE standard. 
The standard curves are: moderate inverse (MI), very inverse (VI) and extremely inverse (EI). The IEEE VI curve is chosen in this paper, but other curves from the IEC standard can be used as well.

\section{Sensitivity Analysis}

The sensitivity analysis is the examination of whether the backup relay is sensitive enough to operate for minimum fault current located at the far end of its primary relay protection zone. This is computed for every coordination pair and is given in (6):

$$
\text { sensitivity }=\frac{I_{s c^{2 \emptyset}{ }_{\text {backup }}}}{k * I_{\text {load }_{\max }}}
$$

where $I_{s c^{2 \phi_{\text {backup }}}}$ is the current that the backup relay senses for the minimum fault simulated at the far end of its primary relay protection zone, $k$ is the temporal overload factor of the backup

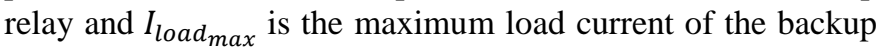
relay.

The sensitivity analysis is a very important matter in the coordination study. For coordination pairs whose backup relays do not fulfill the requirement of sensitivity will lead to very long operation time.

Hence the sensitivity is to be used as a comparative reference for the sensitivity analysis. The sensitivity constraint is given in (7):

$$
\text { sensitivity } \geq 1.5
$$

\section{Differential Evolution Algorithm}

Differential Evolution algorithm (DE) [55-57] is a population-based evolutionary algorithm (EA) consisting of natural selection of genes. In this algorithm, probabilistic distribution is not needed for the generation of offspring. Therefore, it needs less mathematical operations and execution time compared to other EAs. Detailed formulation of DE can be found in [55-57].

\section{1) Initial Population:}

Initiate all parameter vector genes in their feasible range of corresponding relay settings. The initial population matrix is presented in (8):

$$
\mathrm{P}=\left[\begin{array}{cccccc}
\operatorname{dial}_{(1,1)} & \ldots & \operatorname{dial}_{(1, N R)} & k_{(1, N R+1)} & \ldots & k_{(1, N R * 2)} \\
\vdots & \ddots & \vdots & \vdots & \ddots & \vdots \\
\operatorname{dial}_{(N P, 1)} & \ldots & \operatorname{dial}_{(N P, N R)} & k_{(N P, N R+1)} & \ldots & k_{(N P, N R * 2)}
\end{array}\right]
$$

The population size can be defined as $(N P, D * N R)$, where $N P$ represents number of parameter vectors, $D$ number of control variables and $N R$ number of relays.

\section{2) Trigonometric Mutation:}

Three different vector numbers are randomly selected from the DE population for each target vector. Suppose that the selected population members are $\vec{X}_{r_{1}, G}, \vec{X}_{r_{2}, G}, \vec{X}_{r_{3}, G}$ for the $i$-th target vector $\vec{X}_{i, G}$. The indices $r_{1}, r_{2}$ and $r_{3}$ are generated only once for each mutant vector and are mutually exclusive integers randomly chosen from the range $[1, \mathrm{NP}]$, which are also different from the index $i$. According to the equations (10), (11) and (12), three weighting coefficients are formed.

$$
\begin{gathered}
p^{\prime}=\left|f\left(\vec{X}_{r_{1}}\right)\right|+\left|f\left(\vec{X}_{r_{2}}\right)\right|+\left|f\left(\vec{X}_{r_{3}}\right)\right| \\
p_{1}=\left|f\left(\vec{X}_{r_{1}}\right)\right| / p^{\prime} \\
p_{2}=\left|f\left(\vec{X}_{r_{2}}\right)\right| / p^{\prime} \\
p_{3}=\left|f\left(\vec{X}_{r_{3}}\right)\right| / p^{\prime}
\end{gathered}
$$

where $f()$ is the function to be minimized. The trigonometric mutation rate $\Gamma$ is found within the interval $(0,1)$ and the trigonometric mutation scheme is presented in (13) and (14):

$\vec{V}_{i, G+1}=\frac{\vec{X}_{r_{1}}+\vec{x}_{r_{2}}+\vec{X}_{r_{3}}}{3}+\left(p_{2}-p_{1}\right) *\left(\vec{X}_{r_{1}}-\vec{X}_{r_{2}}\right)+\left(p_{3}-p_{2}\right) *$

$\left(\vec{X}_{r_{2}}-\vec{X}_{r_{3}}\right)+\left(p_{1}-p_{3}\right) *\left(\vec{X}_{r_{3}}-\vec{X}_{r_{1}}\right) \quad$ if $\operatorname{rand}[0,1] \leq \Gamma$

$\vec{V}_{i, G+1}=\vec{X}_{r_{1}}+F\left(\vec{X}_{r_{2}}-\vec{X}_{r_{3}}\right) \quad$ else

where $\vec{V}_{i}$ is the donor vector and $F$ is a scalar number that is typically found in the interval $[0.4,1]$. The parameters $\Gamma$ and $F$ are chosen to be 0.5 and 0.8 respectively in this paper.

\section{3) Binomial Crossover:}

The crossover operation is performed after creating the donor vector via mutation. This operation enhances the diversity of the population by exchanging the components of donor vector with the target vector $\vec{X}_{i, G}$ to generate the trial vector $\vec{U}_{i, G}=\left[u_{1, i, G}, u_{2, i, G}, u_{3, i, G}, \ldots, u_{D, i, G}\right]$.

Binomial crossover scheme: whenever a randomly generated number between 0 and 1 is less than or equal to the crossover rate $\mathrm{Cr}$ value for each of the $D$ variables, binomial crossover is performed. Under this circumstance, there will be a nearly uniform distribution of number of parameters inherited from the donor vector. The binomial crossover scheme is presented in (15):

$u_{j, i, G}=\left\{\begin{array}{lr}v_{j, i, G} & \text { if }\left(\operatorname{rand}_{i, j}[0,1] \leq C r \text { or } j=j_{\text {rand }}\right) \\ x_{j, i, G} & \text { otherwise }\end{array}\right.$

where $\operatorname{rand}_{i, j}[0,1]$ is a uniformly distributed random number. This random function is executed for each $j$-th component of the $i$-th parameter vector. Then a randomly chosen index $j_{\text {rand }} \in[1,2, \ldots, D]$ ensures that the trial vector $\vec{U}_{i, G}$ gets at least one component form the donor vector $\vec{V}_{i, G}$. The crossover operation parameter $\mathrm{Cr}$ is selected to be 0.5 in this paper. 


\section{4) Selection:}

The selection operation determines whether the trial or the target vector get through to the following generation, for example at generation $G+1$. The selection operation is presented in (16).

$$
\vec{X}_{i, G+1}= \begin{cases}\vec{U}_{i, G} & \text { if } f\left(\vec{U}_{i, G}\right) \leq f\left(\vec{X}_{i, G}\right) \\ \vec{X}_{i, G} & \text { if } f\left(\vec{U}_{i, G}\right)>f\left(\vec{X}_{i, G}\right)\end{cases}
$$

where $f(\vec{X})$ is the fitness of the target vector and $f(\vec{U})$ is the fitness of the trail vector. If a lower or equal value of fitness is obtained from the new trial vector, then the target vector will be replaced in the next generation; otherwise the target vector is kept in the population. By doing so, the population will never deteriorate since it either gets better or remains the same in fitness quality.

Finally, a pseudo-code of DE algorithm can be formulated as follows:

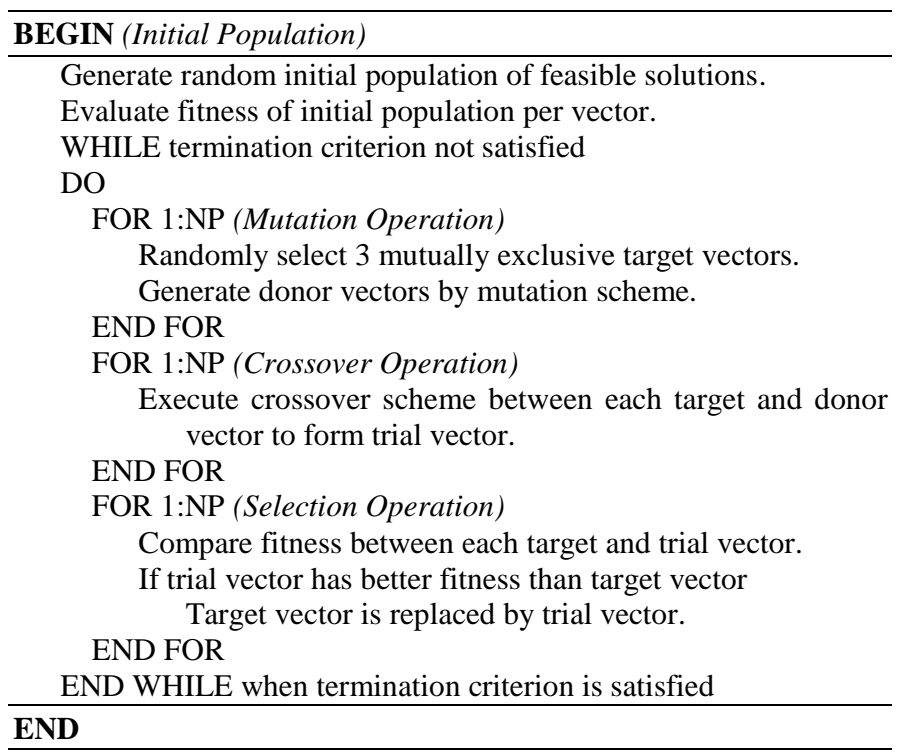

\section{TEST SYSTEM}

The fault currents have been calculated with remote bus breaker opened. The DE algorithm has been simulated with 200 individuals and its sensitive parameters of $\mathrm{DE} C r, \Gamma$ and $F$ have been selected to be $0.5,0.5$ and 0.8 respectively in this paper.

\section{A. Description of 6 Bus System}

A small interconnected 6 bus system was chosen to study the impacts of DGs on relay coordination. The impacts of DGs on the relays are the same in radial and interconnected systems [9-12]. But as the system under study becomes more complex, the impacts of DGs may not be clearly seen since the fault current contribution of the system may be several times greater than the contributions of DGs.

The 6 bus system consists of 10 active phase relays and 16 coordination pairs. A DG farm of $10 \mathrm{MW}$ and $20 \mathrm{MW}$ is connected on bus 6 .

The three cases before employing APS are presented: the base case (DOCRs are coordinated in this case including contingency analysis), the DG10 case (10MW DG inserted on bus 6 with $\mathrm{Xd}$ ' 0.5 used for comparison purpose only since no coordination was carried out) and DG20 case (20MW DG inserted on bus 6 with Xd' 0.3 used for comparison purpose only, no coordination was carried out). For the DG10 and DG20 cases we run power flow and fault analysis including the penetration of DG on bus 6 without contingency analysis and without performing coordination. Then, the relay settings of base case are used to determine the new operation time of the relays (influenced by DG penetration) in order to evaluate the performance of the relays.

The same three cases are presented after employing APS. All three cases are then coordinated including contingency analysis. The 6 bus system is presented in Fig. 7 .

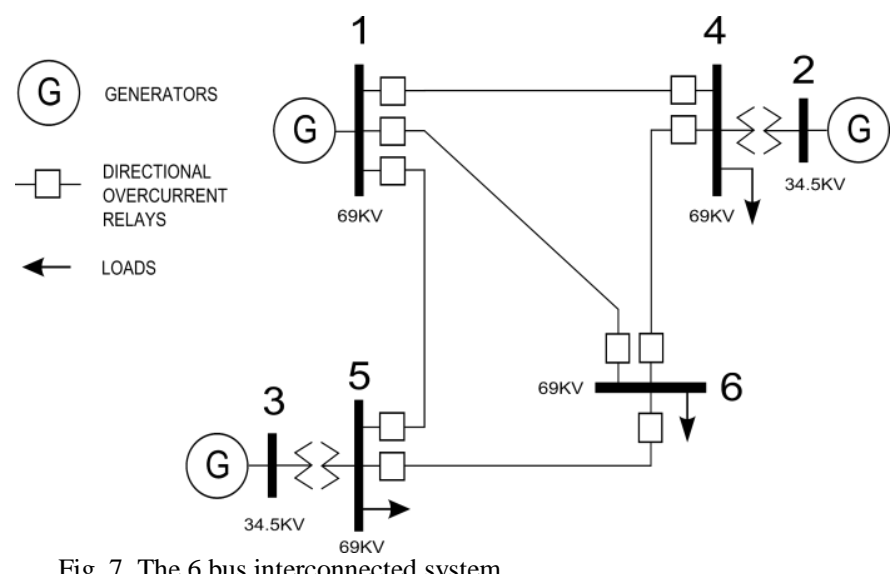

Fig. 7. The 6 bus interconnected system.

\section{B. Description of IEEE 14 Bus System}

A large interconnected IEEE 14 bus system has been chosen to study the overall impacts of DGs on relay coordination.

The system consists of 30 active phase relays and 45 coordination pairs. A DG farm of $30 \mathrm{MW}$ is connected to every bus.

Firstly, DOCRs of the base case are coordinated with no DGs connected. Then, the relay settings of base case are used to determine the new operation time of the relays (influenced by DG, connected to each bus) in order to evaluate the overall degradation and sensitivity improvements of DOCRs.

Finally, sensitivity improvement on a 24-hour basis is presented for the IEEE 14 bus system. The IEEE 14 bus system is presented in Fig. 8. 


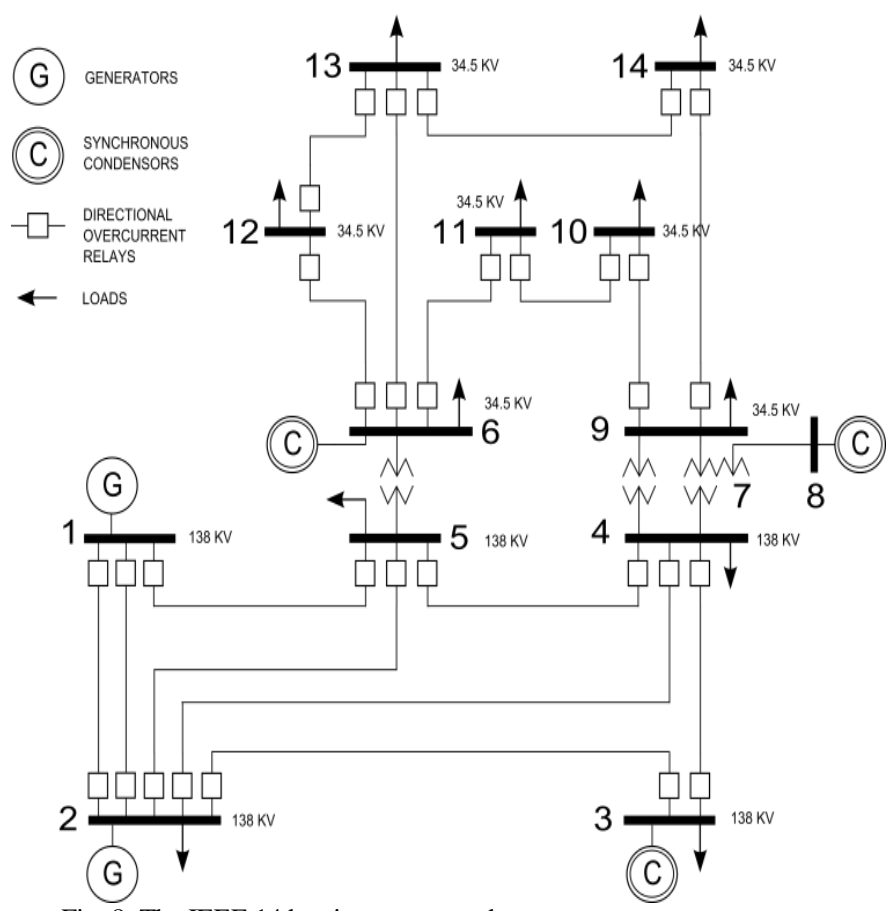

Fig. 8. The IEEE 14 bus interconnected system.

\section{RESUlTS AND DISCUSSIONS}

\section{A. Impacts of DGs on Directional Overcurrent Relay Coordination for 6 Bus System}

The CTI results and short circuit currents for the cases before and after the insertion of DGs are presented in Fig. 9 and Fig. 10.

The threshold line is a visual representation of the preestablished $C T I$ of $0.3 \mathrm{sec}$. It is observed from Fig. 9 (a) and Fig. 10 (a) that the CTI of all 16 coordination pairs of the base case satisfy the constraint presented in (2). The coordination of different pairs of relays for the base case fulfills the expectation of good selectivity since the majority of $C T I$ values are found between 0.3-0.5 sec. But this is not true for the cases DG10 and DG20. From Fig. 9 (a) and Fig. 10 (a) it is observed that several coordination pairs for the cases DG10 and DG20 are found below the threshold value which means that there are violations of constraints when DGs are inserted to the system.

Fig. 9 (b) and Fig. 10 (b) are scaled on the vertical axis to have a clearer view of the changes of primary and backup short circuit currents respectively. Also they are plotted with the CTI results of the same scale on the horizontal axis to observe the infeed and coordination loss effects.

From Fig. 9 (a) the infeed effect of DG penetration can be observed. Whenever there is a significant increase of primary short circuit current, the CTI increases. This is due to the location of DG in the system. The coordination pairs that suffered infeed effect are pairs: 7, 8, 12,14 and 15 as it can be observed from Fig. 9 (a). These pairs suffered infeed effect because the DG is located in-between the two relays. Here, the primary relay will sense higher current magnitude than the base case while the backup relay will sense no change of the current magnitude. The latter effect can be observed from Fig. 10 (b) for the pairs: 7, 8, 12, 14 and 15 where the short circuit current didn't increase.
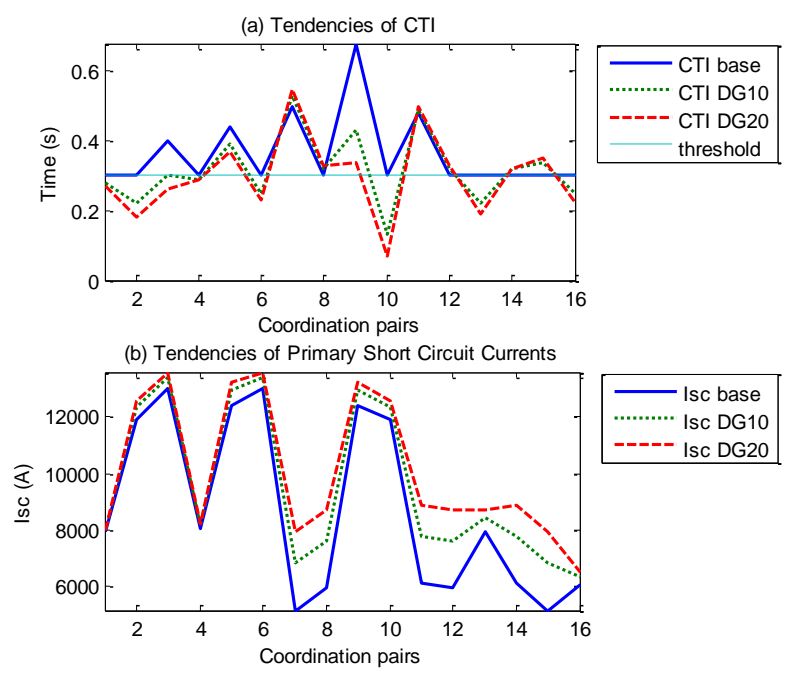

Fig. 9. Tendencies of CTI and primary short circuit currents of the three cases for all 16 coordination pairs.
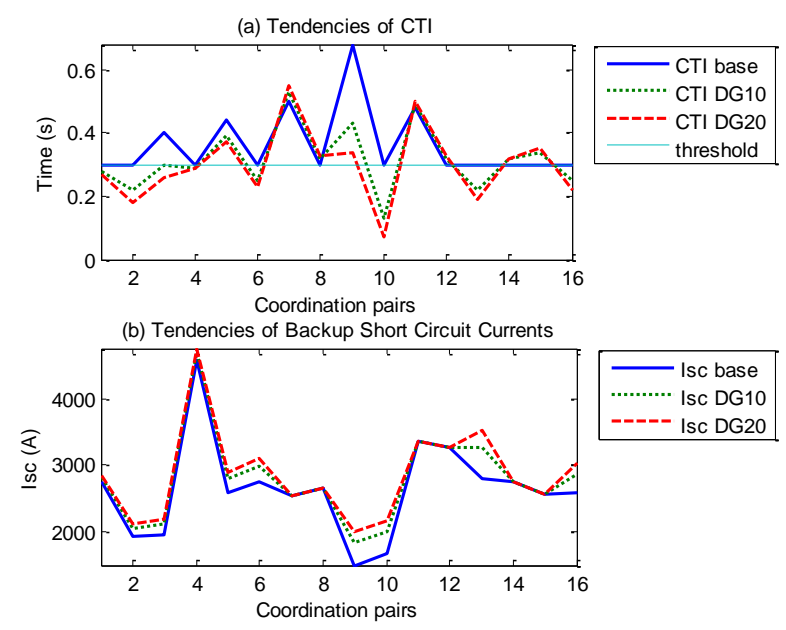

Fig. 10. Tendencies of CTI and backup short circuit currents of the three cases for all 16 coordination pairs.

The infeed effect is not a critical issue since the selectivity is still maintained. The worst scenario is the coordination loss which can be seen from Fig. 10 (a) for the pairs that have CTI values below the threshold. For the cases DG10 and DG20 the pairs: 1, 2, 3, 4, 6, 10, 13 and 16 suffered coordination loss. The cause of coordination loss effect due to the over reach of backup relay is that the DG is located behind both relays. Hence both relays sense an increase of short circuit current, but since the primary relay is situated near the horizontal asymptotic region of the operation characteristic curve; the operation time of the primary relay is barely affected. On the contrary, the backup relay is situated farther from the horizontal asymptotic region; so the operation time of the backup relay is significantly affected. For the pairs: 1, 2, 3, 4, 6, 10, 13 and 16 it can be seen from Fig. 10 (b) and Fig. 9 (b) that there is a significant increase of both the backup and primary short circuit currents; hence the (CTI) coordination is lost for those pairs. 

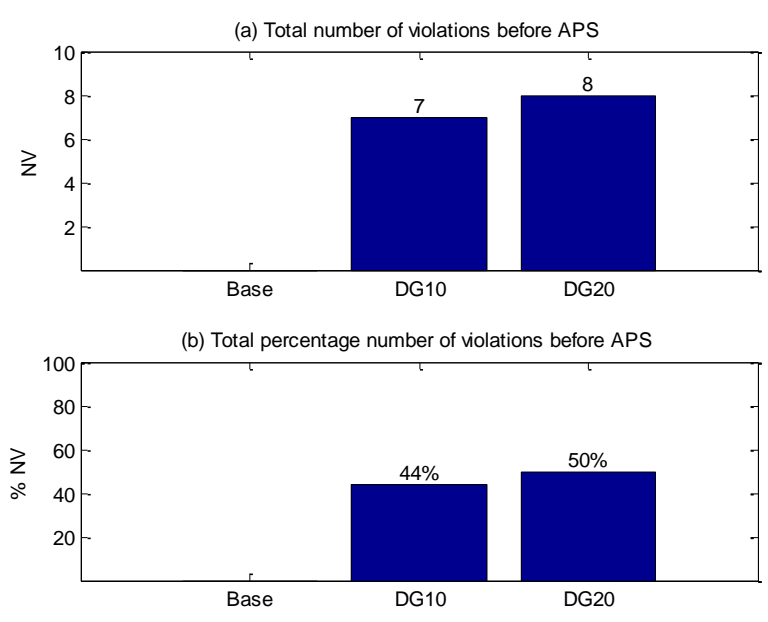

Fig. 11. Number of violations before APS: Comparison among base case, DG10 case and DG20 case.

The number of violations and percentage of violations for the three cases are presented in Fig. 11. From Fig. 11 it is clearly seen that as the capacity of the DG penetration increases, the percentage of number of violations increases as well.

\section{B. Mitigating the Impacts of DGs on Directional Overcurrent Relay Coordination using Adaptive Protection Scheme for 6 Bus System}

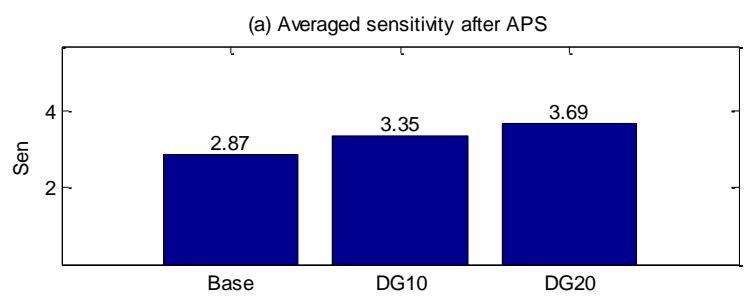

(b) Total percentage of averaged sensitivity improvement after APS

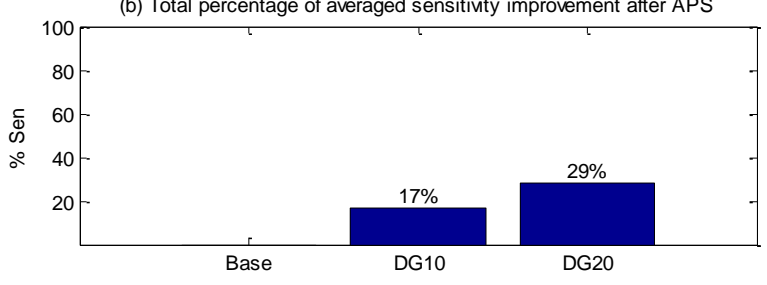

Fig. 12. Averaged sensitivity after APS: Comparison among base case, DG10 case and DG20 case.

The averaged sensitivity and sensitivity improvement percentage for the three cases are presented in Fig. 12. From Fig. 12 it is clearly seen that as the capacity of DG penetration increases, the average sensitivity of the coordination pairs increases as well.

The $C T I$ results for the three cases after the insertion of DGs using adaptive protection scheme are presented in Fig. 13. The results of two-phase short circuit currents, pickup currents and sensitivity are presented Fig. 14.

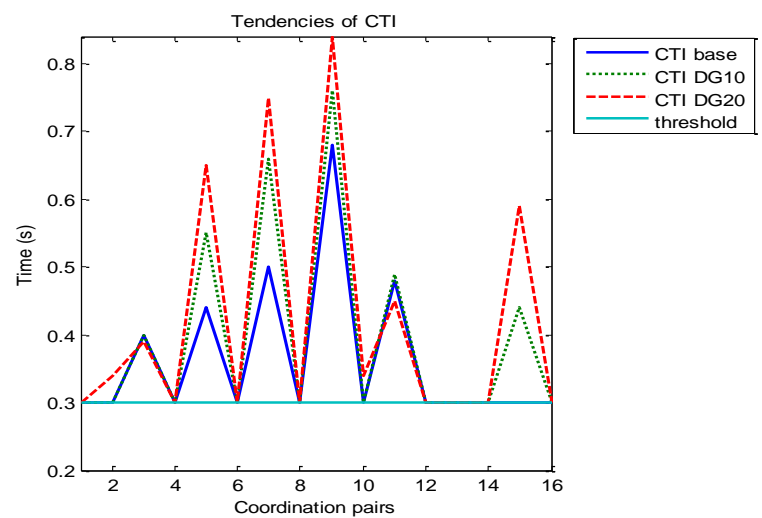

Fig. 13. Tendencies of CTI of the three cases for all 16 coordination pairs employing adaptive protection scheme.

It is observed from Fig. 13 that by employing the adaptive protection scheme; mitigation of coordination loss due to penetration of DG is successfully achieved since there is no violation of coordination constraints for both DG10 and DG20 cases.
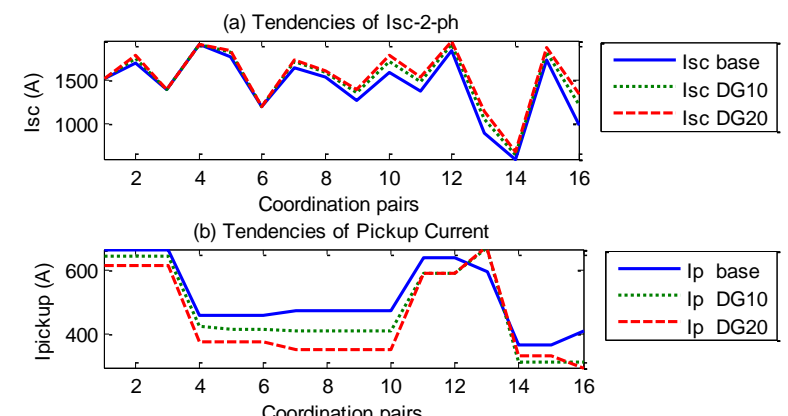

(c) Tendencies of Sensitivity

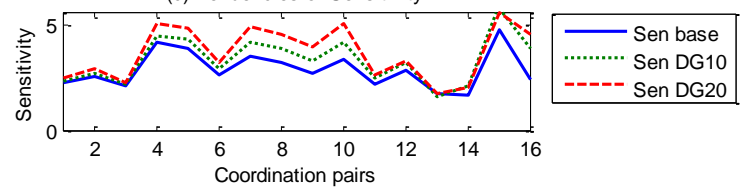

Fig. 14. Tendencies of two-phase short circuit currents, pickup currents and sensitivities of the three cases for all 16 coordination pairs employing adaptive protection scheme.

When adaptive protection scheme is employed for the mitigation of DG penetration impacts, additional benefit can be obtained other than maintaining selectivity for all coordination pairs; namely the increase of sensitivity. From Fig. 14 (a) it can be observed that the 2-phase short circuit current increases as the capacity of DG increases. Also from Fig. 14 (b) it can be observed that the pickup current tend to decrease as the capacity of DG increases. The resulting effect of the observations drawn from Fig. 14 (a) and (b) is the improvement of overall sensitivity as presented in Fig. 14 (c) which coincides with (6) and (7).

The reason why cases DG10 and DG20 have greater CTI values compared to base case, as observed in Fig. 13, is because of the combined effect of increased short circuit current and decreased pickup current caused by DG penetration; as shown 
in Fig. 3 and (5). Both effects lead to shorter operation time, hence APS re-coordinated the system again with increased dial parameters to maintain coordination.

\section{DG Impact and Mitigation on Directional Overcurrent Relay Coordination using Adaptive Protection Scheme for IEEE 14 Bus System}

In this section, an evaluation of DOCRs on IEEE 14 bus system including DG of $30 \mathrm{MW}$ (on each bus) is presented. The causes and effects of DGs are explained in previous sections, therefore, the essence of this section is to show the overall view of DG impacts before and after employing APS on the whole system instead of one fixed location.
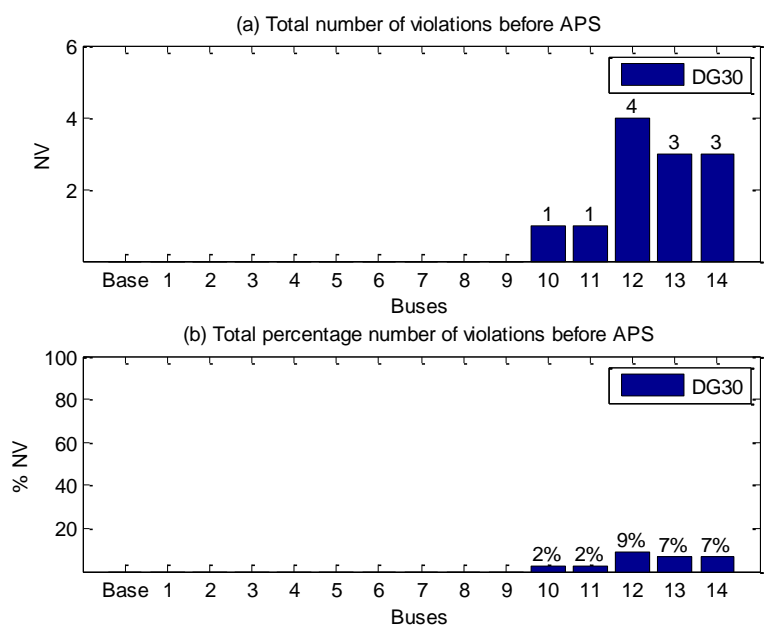

Fig. 15. Number of violations before APS: Comparison among base case and DG30 cases on every bus.

From Fig. 15 it can be seen that as DG is located farther from Gen 1 and 2, more violations appear. This is because the fault contribution of DG is far less than Gen 1 and 2, hence there was no coordination loss when DG is located on buses 1 to 9 that are relatively close to Gen 1 and 2. On the other hand, since contribution of fault currents from Gen 1 and 2 for far buses decreases due to electrical distance (buses 10 to 14), the integration of DG on those buses will degrade protective relay performance and lead to coordination loss. A clear comparison of DG impacts on large or small system can be drawn by observing Fig. 15 (b) and Fig. 11 (b). In Fig. 15 (b) a smaller percentage of violations occurred compared to Fig. 11 (b) since larger system is generally more robust.

The system has zero violation for all cases when DG is connected on each bus when employing APS. Also, sensitivity improvement can be observed. This is presented in Fig. 16 (a) and (b) where one can see a slight increase of sensitivity percentage as DG move away from Gen 1 and 2. The small improvement should not be under-estimated since this effect will be magnified as installed DG capacity will grow.
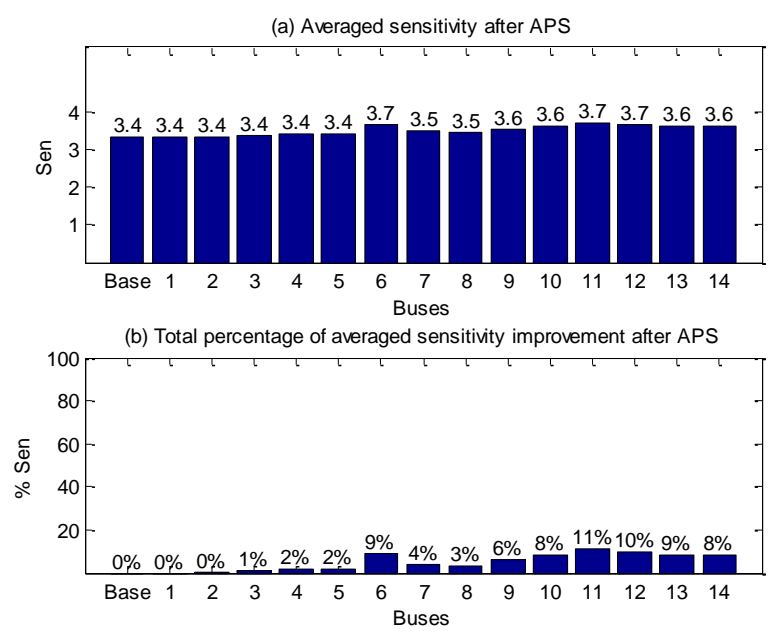

Fig. 16. Averaged sensitivity after APS: Comparison among base case and DG30 cases on every bus.

\section{Evaluation of Directional Overcurrent Relay Sensitivity Improvement with Presence of DG using Adaptive Protection Scheme on a 24 hrs basis}

In this section, an evaluation of the APS on IEEE 14 bus system including DG on bus 13 is presented. The intention is not to show advantage of implementation of APS in a system with DG for mitigation of certain effects (this has been shown clearly in previous sections), but to show the overall possible improvement of sensitivity during the 24-hour period.
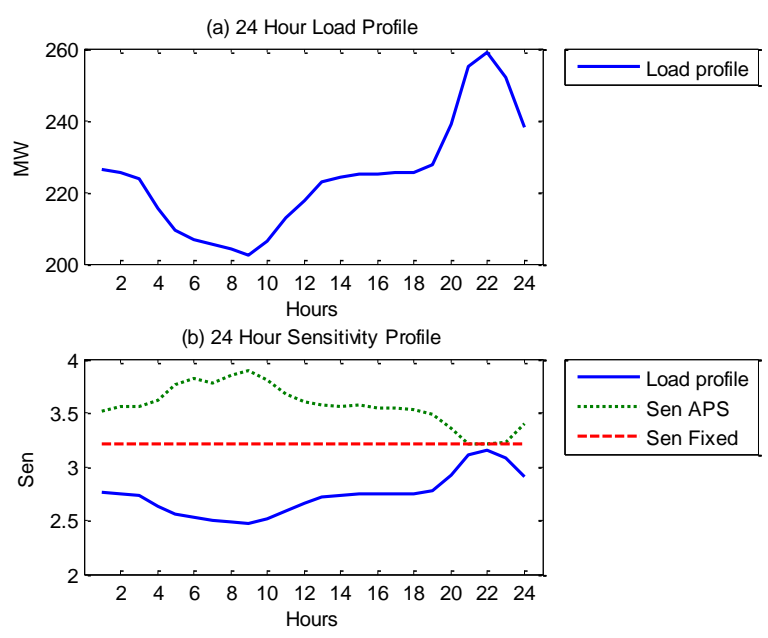

Fig. 17. 24-hour profile of the IEEE 14 bus system: (a) load profile, (b) sensitivity profile for comparison between fixed/conventional relay sensitivity and APS sensitivity.

The 24-hour load profile is a real load profile from the Mexican National Interconnected System (SIN) demand CENACE on the $3^{\text {rd }}$ of April 2016 [66]. This 24-hour profile is applied to the IEEE 14 bus system to approximate the real operation of the system. The 24-hour load profile of the IEEE 14 bus system is presented in Fig. 17 (a). 
From Fig. 17 (b) it can be observed that the fixed sensitivity (conventional coordination approach) has a constant sensitivity throughout 24 hours. On the other hand, the sensitivity of relays using APS increases as the load profile decreases, which yields much better relay sensitivity than using the conventional approach. Since the conventional coordination approach uses maximum load profile to coordinate the relays, the coordination will be maintained for the different load variations as long as the actual load flow does not exceed the maximum load profile. But as it can be observed from Fig. 17 (b), the peak of load profile is rather short; hence substantial overall sensitivity enhancement may be achieved if APS is implemented. The use of maximum load profile as reference for the coordination of protective relays is a prudent approach since advanced communication and control schemes were not available decades ago. However, modern technology permits the implementation of proposed APS which can potentially improve different aspects of relay performance. Hence the APS is proposed and viewed as an important improvement for the future smart grid protective schemes.

\section{CONCLUSION}

Integration of DG in the network surely added numerous operational benefits but at the same time degraded the existing relay performance. The degradation varies depending on the size and location of DG in the network. Likewise, the sensitivity improvement also depends on size and location of DG. Therefore, exploiting the advanced features of relays and with the help of SCADA system, the APS using DE algorithm is proposed for mitigation of DG impacts on electrical networks. Besides, the proposed APS adequately manage both impacts of steady-state load current and fault-state short circuit current contributed by DGs and improves the overall sensitivity of relays.

The proposed scheme offers multiple advantages such as: automatic online coordination, fulfillment of selectivity requirement and overall sensitivity improvement, which at the same time increase the probability of high impedance fault detection. The scheme is robust for future system operational and topological changes.

\section{AKNOWLEDGEMENT}

Dr. Meng Yen Shih was visiting scholar at the Wroclaw University of Science and Technology (WUST-Poland) and would like to thank Consejo Nacional de Ciencia y Tecnología (CONACYT) for the grant of Ph.D scholarship.

\section{APPENDIX}

Numerical comparison tables between "Conventional Protection Scheme (CPS)" and "APS" are presented in this section to complement Section V.
A. Numerical Comparison between Conventional Protection Scheme and Adpative Protection Scheme for 6 Bus System

\begin{tabular}{|c|c|c|c|l|}
\hline \multicolumn{5}{|c|}{ 6 Bus System (DG on Bus 6) } \\
\hline & Base & DG10 & DG20 & \\
\cline { 1 - 4 } NV & 0 & 7 & 8 & \multirow{2}{*}{ CPS } \\
\hline \%NV & -- & $44 \%$ & $50 \%$ & \\
\hline Sen & 2.87 & 2.87 & 2.87 & \\
\hline \%Sen & -- & -- & -- & \\
\hline NV & 0 & 0 & 0 & \multirow{2}{*}{ APS } \\
\hline$\%$ NV & -- & $0 \%$ & $0 \%$ & \\
\hline Sen & 2.87 & 3.35 & 3.69 & \\
\hline$\%$ Sen & -- & $17 \%$ & $29 \%$ & \\
\hline
\end{tabular}

\section{B. Numerical Comparison between Conventional Protection Scheme and Adpative Protection Scheme for IEEE 14 Bus System}

\begin{tabular}{|c|c|c|c|}
\hline \multicolumn{4}{|c|}{ IEEE 14 Bus System (DG on Bus 12) } \\
\hline & Base & DG30 & \\
\cline { 1 - 3 } NV & 0 & 4 & \multirow{2}{*}{ CPS } \\
\hline \%NV & -- & $9 \%$ & \multirow{2}{*}{ APS } \\
\hline Sen & 3.4 & 3.4 & \\
\hline$\%$ Sen & -- & -- & \\
\hline NV & 0 & 0 & \multirow{2}{*}{} \\
\hline \%NV & -- & $0 \%$ & \\
\hline Sen & 3.4 & 3.7 & \\
\hline$\%$ Sen & -- & $10 \%$ & \\
\hline
\end{tabular}

\section{REFERENCES}

[1] M. E. El-Hawary, "The Smart Grid - State-of-the-art and Future Trends," Electric Power Components and Systems, vol. 42, no. 3-4, pp. 239-250, 2014.

[2] Y. Zhang, N. Rahbari-Asr, J. Duan and M.Y. Chow, "Day-Ahead Smart Grid Cooperative Distributed Energy Scheduling With Renewable and Stograge Integration," IEEE Transactions on Sustainable Energy, vol. 7, no. 4, pp. 1739-1748, Oct. 2016.

[3] A. Gholian, H. Mohsenian-Rad and Y. Hua, "Optimal Industrial Load Control in Smart Grid," IEEE Transactions on Smart Grid, vol. 7, no. 5, pp. 2305-2316, Sept. 2016.

[4] X. Su, M.A.S. Masoum and P.J. Wolfs, "Multi-Objective Hierarchical Control of Unbalanced Distribution Networks to Accommodate More Renewable Connections in the Smart Grid Era," IEEE Transactions on Power Systems, vol. 31, no. 5, pp. 3924-3936, Sept. 2016.

[5] Y. Gong, Y. Cai, Y. Guo and Y. Fang, "A Privacy-Preserving Scheme for Incentive-Based Demand Response in the Smart Grid," IEEE Transactions on Smart Grid, vol. 7, no. 3, pp. 1304-1313, May 2016.

[6] F. Kamyab, M. Amini, S. Sheykhha, M. Hasanpour and M.M. Jalali, "Demand Response Program in Smart Grid Using Supply Function Bidding Mechanism," IEEE Transactions on Smart Grid, vol. 7, no. 3, pp. 1277-1284, May 2016.

[7] N. Rahbari-Asr, Y. Zhang and M.Y. Chow, "Consensus-based distributed scheduling for cooperative operation of distributed energy resources and storage devices in smart grids," IET Generation, Transmission \& Distribution, vol. 10, no. 5, pp. 1268-1277, 2016.

[8] N. Rahbari-Asr, Y. Zhang and M.Y. Chow, "Reactive power optimisation considering wind farms based on an optimal scenario method," IET 
Generation, Transmission \& Distribution, vol. 10, no. 15, pp. 3736-3744, 2016.

[9] P.T. Manditereza and R. Bansal, "Renewable distributed generation: The hidden challenges - A review from the protection perspective", Renewable and Sustainable Energy Reviews, vol. 58, pp. 1457-1465, May 2016.

[10] M.M. Eissa, "Protection techniques with renewable resources and smart grids - A survey", Renewable and Sustainable Energy Reviews, vol. 52, pp. 1645-1667, Dec. 2015.

[11] I. Colak, S. Sagiroglu, G. Fulli, M. Yesibudak and C.F. Covrig, "A survey on the critical issues in smart grid technologies", Renewable and Sustainable Energy Reviews, vol. 54, pp. 396-405, Feb. 2016.

[12] X. Liang, "Emerging Power Quality Challenges Due to Integration of Renewable Energy Sources", IEEE Transactions on Industry Applications, vol. 53, no. 2, pp. 855-866, Mar-Apr 2017.

[13] S. Montoya-Bueno, J.I. Munoz-Hernandez and J. Contreras, "Uncertainty management of renewable distributed generation", Journal of Cleaner Production, vol. 138, part 1, pp. 103-118, Dec. 2016.

[14] S.S. Kaddah, M.M. El-Saadawi and D.M. El-Hassanin, "Influence of Distributed Generation on Distribution Networks During Faults," Electric Power Components and Systems, vol. 43, no. 16, pp. 1781-1792, 2015

[15] M.A. Haj-ahmed and M.S. Illindala, "The Influence of Inverter-Based DGs and Their Controllers on Distribution Network Protection", IEEE Transactions on Industry Applications, vol. 50, no. 4, pp. 2928-2937, July-Aug. 2014.

[16] A. Kamel, M.A. Alaam, A.M. Azmy and A.Y. Abdelaziz, "Protection Coordination for Distribution Systems in Presence of Distributed Generators," Electric Power Components and Systems, vol. 41, no. 15, pp. 1555-1566, 2013.

[17] H. Zayandehroodi, A. Mohamed, H. Shareef and M. Mohammadjafari, "Impact of distributed generations on power system protection performance", International Journal of the Physical Sciences, vol. 6, no. 16, pp. 3873-3881, August. 2011.

[18] W. El-Khattam and T. S. Sidhu, "Restoration of directional overcurrent relay coordination in distributed generation systems utilizing fault current limiter," IEEE Transactions on Power Delivery, vol. 23, no. 2, pp. 576585, April 2008.

[19] J. C. Gómez and M. M. Morcos, "Coordination of voltage sag and overcurrent protection in DG system," IEEE Transactions on Power Delivery, vol. 20, no. 1, pp. 214-218, January 2005.

[20] W. El-Khattam and T. S. Sidhu, "Resolving the impact of distributed renewable generation on directional overcurrent relay coordination: A case study," IET Renewable Power Generation, vol. 3, no. 4, pp. 415425, 2009.

[21] C. J.Mozina, "A tutorial on the impact of Distributed Generation (DG) on distribution systems," in Proc. Protective Relay Eng. Annu. Conf., pp. 591-609, 2008.

[22] R. A. Walling, R. Saint, R. C. Dugan, J. Burke, and L. A. Kojovic, "Summary of distributed resources impact on power delivery system," IEEE Transactions on Power Delivery, vol. 23, no. 3, pp. 1636-1644, July 2008.

[23] S. Conti, "Analysis of distribution network protection issues in presence of dispersed generation", Electric Power System Research, vol. 79, pp. 49-56, 2009.

[24] S. Chaitusaney and A. Yokoyama, "Prevention of reliability degradation from recloser-Fuse miscoordination due to distributed generation," IEEE Transactions on Power Delivery, vol. 23, no. 4, pp. 2545-2554, Octuber 2008.

[25] J. Chen, R. Fan, X. Duan, and J. Cao, "Penetration level optimization for DG considering reliable action of relay protection device constrains," in Proc. Int. Conf. Sustain. Power Gen. Supply, pp. 1-5, 2009.

[26] T. K. Abdel-Galil, A. E. B. Abu-Elnien, E. F. El-saadany, A. Girgis, Y. A.-R. I. Mohamed, M. M. A. Salma, and H. H.M. Zeineldin, "Protection coordination planning with distributed generation," Canmet Energy Technol. Ctr., Varennes, QC, Canada, CETC-Varennes 2007-149 (TR), 2007.

[27] H. B. Funmilayo and K. L. Buyler-Purry, "An approach to mitigate the impact of distributed generation on the overcurrent protection scheme for radial feeders," in Proc. IEEE Power Syst. Conf. Expo., pp. 1-11, 2009.

[28] F. A. Viawan, D. Karlsson, A. Sannino, and J. Daalde, "Protection scheme for meshed distribution systems with high penetration of distributed generation," in Proc. Pow. Sys. Conf. Advanced Meter., Protect. Control, Commun., Distrib. Recources, pp. 99-104, 2006.

[29] I. M. Chilvers, N. Jenkins, and P. A. Crossley, "The use of $11 \mathrm{kV}$ distance protection to increase generation connected to the distribution network," in Proc. Int. Conf. Develop. Power Syst. Protect., vol. 2, pp. 551-554, 2004.

[30] D. Uthitsunthorn and T. Kulworawanichpong, "Distance protection of a renewable energy plant in electric power distribution systems," in Proc. Int. Conf. Power Syst. Technol., pp. 1-4, 2010.

[31] S.B. Naderi, M. Negnevitsky, A. Jalilian, M. Hagh and K. Muttaqi, "Optimum Resistive Type Fault Current Limiter: An Efficient Solution to Achieve Maximum Fault Ride-through Capability of Fixed Speed Wind Turbines during Symmetrical and Asymmetrical Grid Faults", IEEE Transactions on Industry Applications, vol. 53, no. 1, pp. 538-548, JanFeb, 2017.

[32] A. Esmaeili, S. Esmaeili and H. Hojabri, "Short-circuit level control through a multi-objective feeder reconfiguration using fault current limiters in the presence of distributed generations", IET Generation, Transmission \& Distribution, vol. 10, no. 14, pp. 3458-3469, 2016.

[33] T. Ghanbari, E. Farjah and N. Tashakor, "Thyristor based bridge-type fault current limiter for fault current limiting capability enhancement", IET Generation, Transmission \& Distribution, vol. 10, no. 9, pp. 22022215, 2016.

[34] W. Guo, L. Xiao and S. Dai, "Fault current limiter-battery energy storage system for the doubly-fed induction generator: analysis and experimental verification", IET Generation, Transmission \& Distribution, vol. 10, no. 3, pp. 653-660, 2016

[35] Y. Kim, H.C. Jo and S.K. Joo, "Analysis of Impacts of Superconducting Fault Current Limiter (SFCL) Placement on Distributed Generation (DG) Expansion", IEEE Transactions on Applied Superconductivity, vol. 26, No. 4, June 2016

[36] H. He, L. Chen, T. Yin, Z. Cao, J. Yang, X. Tu and L. Ren, "Application of a SFCL for Fault Ride-Through Capability Enhancement of DG in a Microgrid System and Relay Protection Coordination", IEEE Transactions on Applied Superconductivity, vol. 26, No. 7, Oct. 2016.

[37] A. Elmitwally, E. Gouda and S. Eladawy, "Optimal allocation of fault current limiters for sustaining overcurrent relays coordination in a power system with distributed generation", Alexandria Engineering Journal, vol. 54, no. 4 pp. 1077-1089, Dec. 2015.

[38] Hamid Javadi, S.M. Ali Mousavi and Mojtaba Khederzadeh, "A novel approach to increase FCL application in preservation of over-current relays coordination in presence of asynchronous DGs", International Journal of Electrical Power and Energy Systems, vol. 44, pp.810-815, 2013.

[39] Sung-Hun Lim, Jin-Seok Kim, Myong-Hyon Kim and Jae-Chul Kim, "Improvement of Protection Coordination of Protective Devices Through Application of a SFCL in a Power Distribution System with a Dispersed Generation", IEEE Transactions on Applied Superconductivity, vol. 22, No. 3, June 2012.

[40] Sung-Hun Lim and Jae-Chul Kim, "Analysis on Protection Coordination of Protective Devices with a SFCL due to the Application Location of a Dispersed Generation in a Power Distribution System ", IEEE Transactions on Applied Superconductivity, vol. 22, No. 3, June 2012.

[41] H. Yamaguchi and T. Kataoka, "Current limiting characteristics of transformer type superconducting fault current limiter with shunt impedance and inductive load," IEEE Transactions on Power Delivery, vol. 23, no. 4, pp. 2545-2554, Octuber 2008.

[42] Y. Zhang and R. A. Dougal, "Novel dual-FCL connection for adding distributed generation to a power distribution utility," IEEE Transactions on Applied Superconductivity, vol. 21, no. 3, pp. 2179-2183, June 2011.

[43] Esmaeil Ebrahimi, Mohammad Javad Sanjari and Gevork B. Gharehpetian, "Control of three-phase inverter-based DG system during fault condition without changing protection coordination", International Journal of Electrical Power and Energy Systems, vol. 63, pp.814-823, 2014.

[44] Hesam Yazdanpanahi, Wilsun Xu, and Yun Wei Li, "A Novel Fault Current Control Scheme to Reduce Synchronous DG's Impact on Protection Coordination", IEEE Transactions on Power Delivery, vol. 29, No. 2, pp. 542-551, 2014.

[45] R. Sitharthan, M. Geethanjali and T. K. S. Pandy, "Adaptive protection scheme for smart microgrid with electronically coupled distributed 
generations", Alexandria Engineering Journal, vol. 55, no. 3 pp. 25392550 , Sept. 2016.

[46] A. Rahmati, M.A. Dimassi, R. Adhami and D. Bumblauskas, "An Overcurrent Protection Relay Based on Local Measurements", IEEE Transactions on Industry Applications, vol. 51, no. 3, pp. 2081-2085, May-June 2015.

[47] S.C. Hsieh, C.S. Chen, C.T. Tsai, C.T. Hsu and C.H. Lin "Adaptive Relay Setting for Distribution Systems Considering Operation Scenarios of Wind Generators", IEEE Transactions on Industry Applications, vol. 50, no. 2, pp. 1356-1363, March-April 2014.

[48] Sukumar M. Brahma and Adly A. Girgis,"Development of Adaptive Protection Scheme for Distribution Systems With High Penetration of Distributed Generation", IEEE Transactions on Power Delivery, vol. 19, No. 1, pp. 56-63, January 2004.

[49] H. Wan, K. K. Li, and K. P. Wong, "An adaptive multiagent approach to protection relay coordination with distributed generators in industrial power distribution system," IEEE Transactions on Industry Applications, vol. 46, no. 5, pp. 2118-2124, Sep./Oct. 2010.

[50] Ma J, Wang X, Zhang Y, Yang Q, Phadke AG., "A novel adaptive current protection scheme for distribution systems with distributed generation", International Journal of Electrical Power and Energy Systems, vol. 43, issue 1, pp.1460-1466, 2012.

[51] J. Ma, J. Li, and Z.Wang, "An adaptive distance protection scheme for distribution system with distributed generation," in Proc. 5th Int. Conf. Crit. Infrastruct., pp. 1-4, 2010.

[52] M. Baren and I. El-Markabi, "Adaptive overcurrent protection for distribution feeders with distributed generators," in Proc. Power Syst. Conf. Expo., vol. 2, pp. 715-719, 2004.

[53] Y. Ates, A.R. Boynuegri, M. Uzunoglu, A. Nadar, R. Yumurtaci, O. Erdinc, N.G. Paterakis and J.P.S. Catalao, "Adaptive Protection Scheme for a Distribution System Considering Grid-Connected and Islanded Modes of Operation”, Energies, Special Issue: Distributed Renewable Generation, vol. 9, no. 5, pp. 1-18, May 2016.

[54] M.Y. Shih, A. Conde, Z.M. Leonowicz and L. Martirano, "Mitigating the Impact of Distributed Generation on Directional Overcurrent Relay Coordination by Adaptive Protection Scheme", 16th IEEE International Conference on Environment and Electrical Engineering (EEEIC), pp. 16, June 2016.

[55] S. Das and P.N. Suganthan, "Differential Evolution: A Survey of the State of the Art", IEEE Trans. Evolution. Computat., vol. 15, No. 1, pp. 4-31, Feb. 2011.

[56] S. Das, S.S. Mullick and P.N. Suganthan, "Recent advances in Differential Evolution - An updated survey", Swarm and Evolutionary Computation., vol. 27, pp. 1-30, April. 2016.

[57] M.N. Alam, B. Das and V. Pant, "A comparative study of metaheuristic optimization approaches for directional overcurrent relays coordination", Electric Power System Research, vol. 128, pp. 39-52, Nov. 2015.

[58] Electric Power Research Institute (EPRI) Smart Grid Resource Center, available at: http://smartgrid.epri.com/.

[59] S.A. Saleh, E. Ozkop and A.S. Aljankawey, "The Development of a Coordinated Anti-Islanding Protection for Collector Systems With Multiple Distributed Generation Units", IEEE Transactions on Industry Applications, vol. 52, no. 6, pp. 4656-4667, Nov.-Dec. 2016.

[60] A. Tavakoli, M. Negnevitsky and K. Muttaqi, "A Decentralized Model Predictive Control for Operation of Multiple Distributed Generators in an Islanded Mode", IEEE Transactions on Industry Applications, vol. 53, no. 2, pp. 1466-1475, Mar-Apr 2017.

[61] G. Marchesan, M.R. Muraro, G. Cardoso Jr, L. Mariotto and C.D.L. de Silva, "Method for distributed generation anti-islanding protection based on singular value decomposition and linear discrimination analysis", Electric Power Systems Research, vol. 130, pp. 124-131, Jan. 2016.

[62] J. Mitra, M.R. Vallem and C. Singh, "Optimal Deployment of Distributed Generation Using a Reliability Criterion", IEEE Transactions on Industry Applications, vol. 52, no. 3, pp. 1989-1997, May-June 2016.

[63] IEEE Guide for Protective Relay Applications to Distribution Lines, IEEE std C37.230-2007

[64] J. Lewis Blackburn, and Thomas J. Domin, "Protective relaying, principles and applications", 3rd edition, 2006.

[65] IEEE Standard Inverse-Time Characteristic Equations for Overcurrent Relays, IEEE std C37.112-1996.

[66] CENACE webpage, http://www.cenace.gob.mx/GraficaDemanda.aspx.

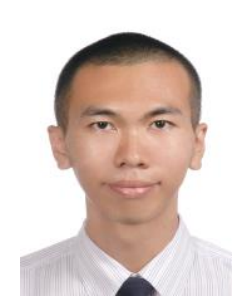

Meng Yen Shih received the B.Eng. degree in electrical engineering from Instituto Tecnológico de Chetumal (ITCH) in 2010, and both the M.Sc. and Ph.D degrees in electrical engineering from Universidad Autónoma de Nuevo León (UANL) in 2013 and 2016 respectively. He is currently Professor at Universidad de Quintana Roo (UQROO) and his research interests are power system protection, distributed generation and evolutionary algorithms.

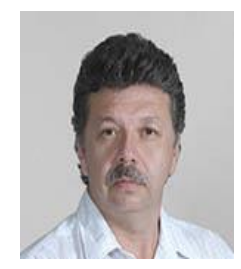

Arturo Conde received the M.Sc. and Ph.D. degrees in Electric Engineering from the Universidad Autónoma de Nuevo León, Mexico in 1996 and 2002 respectively. Currently he is Professor at the graduate program of electrical engineering in the same University, member of the National Research System of Mexico. His research interests include adaptive protection of power systems, optimal energy management, and smart grid systems.

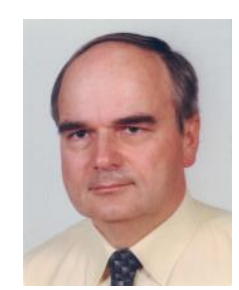

Zbigniew Leonowicz (IEEE M'03-SM'12) received the M.Sc., Ph.D. and Habilitate Doctorate (Dr Sc.) degrees, all in Electrical Engineering, in 1997, 2001, and 2012, respectively. He has been with the Department of Electrical Engineering, Wroclaw University of Science and Technology, since 1997 where he currently holds the position of Associate Professor. His current research interests are in the areas of power quality, control and protection of power systems, renewables, industrial ecology and applications of advanced signal processing methods in power systems.

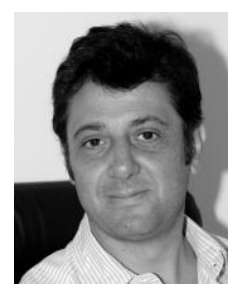

Luigi Martirano (IEEE M'02-SM'11) received the M.Sc. and Ph.D. degrees, in Electrical Engineering, in 1998 and 2003, respectively. He has been with the Department of Electrical Engineering, Sapienza University of Rome (Italy), since 2000 where he currently holds the position of Associate Professor. His current research interests are in the areas of power systems design, planning, safety, lightings, home and building automation, energy management. $\mathrm{He}$ is a senior member of the IEEE/IAS, member of the CEI (Italian Electrical Commission) Technical Committees CT205 (Home and Building Electronic Systems) and CT315 (Energy Efficiency) and member of the European CENELEC Joint Working Group CEN/CLC JWG9 "Energy measurement plan for organizations" 